\title{
Produção e qualidade do fruto da mamona em semeio e rebrote sob estresse hídrico fenológico
}

\author{
José E. B. da Silva', Hugo O. C. Guerra', Rogério D. de Lacerda ${ }^{2}$, \\ Genival Barros Júnior ${ }^{3}$ \& Leoberto de A. Formiga ${ }^{4}$
}

\begin{abstract}
RESUMO
A mamona tem grande importância socioeconômica na região Nordeste, em virtude da inclusão social e da garantia de empregos. O estudo objetivou pesquisar a sensibilidade da mamona a vários níveis de água disponível no solo em diferentes estágios fenológicos avaliando-se os efeitos na produtividade e na qualidade dos frutos em condições de semeio e rebrote. O delineamento experimental foi o de blocos ao acaso, em esquema fatorial 2 × 4 (2 cultivares: BRS Paraguaçu e BRS Nordestina e 4 níveis de água no solo: 40, 60, 80 e 100\% aplicados nas fases de crescimento e frutificação) com três blocos. Os resultados foram submetidos a análise de variância F, teste de Tukey, para comparação dos cultivares e análise de regressão para a água disponível. O aumento da água no solo nos diferentes estádios fenológicos promoveu alterações significativamente positivas na produtividade e na qualidade do fruto dos dois cultivares. Ambos os ciclos, semeio e rebrote, apresentaram desempenho semelhante ressaltando-se que o melhor desempenho da mamona foi obtido quando o conteúdo de água do solo se manteve durante todo o ciclo fenológico da planta, com $100 \%$ da água disponível no solo para as plantas.
\end{abstract}

Palavras-chave: Ricinus communis L., manejo da poda, irrigação

\section{Production and fruit quality of castor bean in seeding and regrowth under phenological water stress}

\begin{abstract}
The castor bean crop has a social and economical importance for the Northeast region due to the social inclusion and employment. The experiment aimed to study the sensitivity of the castor bean to soil water levels applied at different phenological stages, evaluating the production and fruit quality in the seeding and regrowth cycles. The experimental design was a randomized block in a $2 \times 4$ factorial scheme, consisting of two castor bean cultivars (BRS Paraguaçu and BRS Nordestina) and 4 levels of available soil water (40, 60,80 , e $100 \%$ ) applied during growth and frutification with three replications. The data were analysed statistically through analysis of variance ( $F$ teste) and Tukey test was used for the comparison of the cultivars and regression analysis for the quantitative factor. The increase of soil water availability for the plant at the different phenological stages studied increased production significantly and promoted positive alterations in the fruit quality of both cultivars. Both cycles presented similar performance with an elevated quality of the final product. The best performance of the castor bean was obtained when the available soil water content during the whole phenological period was kept at $100 \%$.
\end{abstract}

Key words: Ricinus communis L., pruning management, irrigation 


\section{INTRODUÇÃO}

A mamona (Ricinus communis L.), planta cosmopolita de origem tropical, é cultivada tradicionalmente em pequenas e médias propriedades, o que potencializa seu valor social como geradora de renda e de empregos no campo (Oliveira \& Zanotto, 2008); seu cultivo é plenamente necessário para a região Nordeste em virtude da inclusão social, garantia de empregos e divisas ao país, dada à sua aptidão para produção de energia (Costa et al., 2006).Com teor de óleo nas sementes de aproximadamente $48 \%$, é uma espécie vegetal que apresenta uma perspectiva aceitável para o cultivo visando à produção de biodiesel. O óleo de mamona ou de rícino extraído das sementes tem características singulares classificando-o como um dos mais versáteis da natureza. Isto possibilita uma ampla gama de utilização industrial com utilidade só comparável à do petróleo com vantagem, porém, de ser um produto renovável o que dá, à cultura, um potencial econômico relevante e estratégico ao Brasil (Azevedo \& Beltrão, 2007).Produz quantidade considerável de biomassa, suas folhas podem servir de alimento para o bicho da seda, as hastes contêm celulose para fabricação de papel e das sementes são obtidos o óleo e a torta, ricos em proteína (Cavalcante et al., 2005).

Pelo fato de ter um sistema radicular robusto e denso, que explora camadas profundas de solo, é considerada uma cultura tolerante ao déficit hídrico (Ramos et al., 2006). Isto faz que a cultura se apresente produtiva o ano inteiro na Região Nordeste do Brasil, caracterizada por apresentar, durante a maior parte do ano, solos com capacidade de armazenamento de água abaixo da sua satisfação plena (Amorim Neto et al.,2001), constituindo, deste modo, alternativa importante para o semiárido do Brasil. O cultivo da mamoneira sob irrigação no Brasil é, no entanto, recomendado para áreas nas quais já tenham sido registradas produtividades superiores a seis toneladas por hectare razão por que é conveniente investir em pesquisas relacionadas à demanda hídrica desta cultura a fim de se obter informações sobre o manejo da irrigação com vistas ao ganho de produtividade, aumento na sua eficiência produtiva (Beltrão et al., 2006) e também para preservação do meio ambiente (Gomes \& Testezlaf, 2007).

Como as demais culturas, o crescimento, o desenvolvimento e a produção da mamona, são plenamente satisfeitos mediante um suprimento hídrico diferenciado para suas diferentes fases fenológicas compatíveis com sua capacidade de retirada de água na zona padrão de absorção pelas raízes evitando desperdício de água e saturação da área de cultivo (Barreto,2004). Assim, o conhecimento do efeito da irrigação diferenciada por fase fenológica da mamoneira possibilita a economia de água, energia elétrica e mão-de-obra em cada estação de cultivo, reduzindo os custos de produção, mas contribuindo com a sustentabilidade hidroambiental.
Visando à redução dos custos de implantação da lavoura, a poda da mamoneira já é muito utilizada no Brasil e se constitui em importante manejo para exploração da ricinocultura em segundo ciclo. Além da redução dos custos de produção no segundo ciclo (rebrote) diminui o porte das plantas facilitando as operações de colheita além de estimular a emissão de ramos laterais e o consequente aumento de rendimento da cultura (Azevedo \& Beltrão, 2007). Diniz et al. (2009) observaram, podando a mamona com diferentes populações de plantas, uma redução do tamanho da planta sem isto afetar a produtividade. Segundo Ambroszczyk et al.(2008), trabalhando com batata a poda drástica exerce efeito positivo sobre a irradiação recebida pela planta. O sucesso da poda, segundo Cebula (1996) é determinado pela variedade, pelo espaçamento e pelas condições de crescimento da planta.

$\mathrm{Na}$ busca de fatores capazes de influenciar positivamente o desempenho da cultura objetivou-se, com esta pesquisa, estudar a sensibilidade de dois cultivares de mamona (BRS Paraguaçu e BRS Nordestina) quando submetidos a diferentes conteúdos de água disponível no solo, em diversas fases do ciclo fenológico durante o semeio e o rebrote.

\section{Material e Métodos}

O experimento foi realizado em condições de campo no Centro de Ciências Agrárias e Ambientais - CCAA, Campus II da Universidade Estadual da Paraíba - UEPB, localizado no Sítio Imbaúba, Zona Rural do Município de Lagoa Seca - PB, Microrregião de Campina Grande, Agreste Paraibano, entre outubro de 2008 e outubro de 2009; tem altitude média de $634 \mathrm{~m}$ e coordenadas geográficas: $7^{\circ} 15^{\prime}$ $18^{\prime \prime} \mathrm{S}$ e $35^{\circ} 52^{\prime} 28^{\prime \prime} \mathrm{W}$.

O solo predominante na área de estudo é o Neossolo Regolito Eutrófico, com textura franco-arenosa e baixo teor de matéria orgânica. Suas características físico-hídricas e químicas se encontram nas Tabelas 1 e 2, respectivamente, conforme análises realizadas no Laboratório de Irrigação e Salinidade (LIS) da UFCG, seguindo a metodologia proposta pela EMBRAPA (1997).

A mamona foi semeada na profundidade média de $3 \mathrm{~cm}$ tendo-se lançado quatro sementes por cova. Antes do semeio adubou-se o solo com superfosfato triplo em fundação, na quantidade de $120 \mathrm{~kg} \mathrm{ha}^{-1}$ de $\mathrm{P}_{2} \mathrm{O}_{5}$ e $100 \mathrm{~kg} \mathrm{ha}^{-1}$ de $\mathrm{K}_{2} \mathrm{O}$ na forma de cloreto de potássio e nitrogênio na forma de sulfato de amônia dividido em intervalos de 10 dias aplicados via fertirrigação, com a primeira aplicação 20 dias após o semeio, conforme EMBRAPA (2007).

Utilizou-se o delineamento experimental em blocos ao acaso, no esquema fatorial $2 \times 4$, constituído pelos dois cultivares de mamona e pelos quatro níveis de água disponível, aplicados em diferentes fases fenológicas, com 3 blocos (Tabela 3).

Tabela 1. Atributos físicos-hídricos do solo da área do experimento

\begin{tabular}{|c|c|c|c|c|c|c|c|c|}
\hline \multirow{2}{*}{\multicolumn{3}{|c|}{ Granulometria $\left(\mathrm{g} \mathrm{kg}^{-1}\right)$}} & \multirow{3}{*}{$\begin{array}{c}\text { Classificação } \\
\text { textural }^{*}\end{array}$} & \multirow{2}{*}{\multicolumn{2}{|c|}{ Densidade $\left(\mathrm{kg} \mathrm{dm}^{-3}\right)$}} & \multirow{3}{*}{ Porosidade } & \multicolumn{2}{|c|}{ Conteúdo de água } \\
\hline & & & & & & & CC & PM \\
\hline Argila & Silte & Areia & & Solo & Partículas & & \multicolumn{2}{|c|}{$\mathrm{m}^{3} \mathrm{~m}^{-3}$} \\
\hline 177,6 & 110,4 & 712,0 & Franco Arenoso & 1,42 & 2,65 & 0,4943 & 0,1780 & 0,0589 \\
\hline
\end{tabular}

* Classificação segundo o Departamento de Agricultura dos Estados Unidos (USDA); CC - Capacidade de campo, PMP - ponto de murcha permanente 
Tabela. 2. Características químicas do solo da área do experimento

\begin{tabular}{lc}
\hline \multicolumn{1}{c}{ Característica } & Resultado \\
Cálcio $\left(\mathrm{cmol}_{\mathrm{c}} \mathrm{kg}^{-1}\right)$ & 3,16 \\
Magnésio $\left(\mathrm{cmol}_{\mathrm{c}} \mathrm{kg}^{-1}\right)$ & 2,46 \\
Sódio $\left(\mathrm{cmol}_{\mathrm{c}} \mathrm{kg}^{-1}\right)$ & 0,05 \\
Potássio $\left(\mathrm{cmol}_{\mathrm{c}} \mathrm{kg}^{-1}\right)$ & 0,14 \\
Soma de Bases $\left(\mathrm{cmol}_{\mathrm{c}} \mathrm{kg}^{-1}\right)$ & 5,84 \\
Hidrogênio $\left(\mathrm{cmol}_{\mathrm{c}} \mathrm{kg}^{-1}\right)$ & 3,72 \\
Alumínio $\left(\mathrm{cmol}_{\mathrm{c}} \mathrm{kg}^{-1}\right)$ & 0,06 \\
CTC $\left(\mathrm{cmol}_{\mathrm{c}} \mathrm{kg}^{-1}\right)$ & 9,62 \\
Carbonato de cálcio qualitativo & Ausência \\
Carbono orgânico $\left(\mathrm{g} \mathrm{kg}^{-1}\right)$ & 6,70 \\
Matéria orgânica $\left(\mathrm{g} \mathrm{kg}^{-1}\right)$ & 11,50 \\
Nitrogênio $\left(\mathrm{g} \mathrm{kg}^{-1}\right)$ & 0,63 \\
Fósforo assimilável $\left(\mathrm{mg} \mathrm{dm}^{-1}\right)$ & 5,21 \\
pH em água $(1: 2,5)$ & 6,78 \\
Condutividade elétrica $\left(\mathrm{dS} \mathrm{m}^{-1}\right)$ & 0,14 \\
\hline
\end{tabular}

Tabela 3. Tratamentos e fases fenológicas nas quais ocorreu a variação nos níveis de irrigação

\begin{tabular}{ccccc}
\hline Regime & $\begin{array}{c}\text { Crescimento } \\
\text { (0-60 dias) }\end{array}$ & $\begin{array}{c}\text { Floração } \\
\text { (61-89 dias) } \\
\text { Níveis de água disponível (\%) }\end{array}$ & $\begin{array}{c}\text { Frutificação } \\
\text { (90-150 dias) }\end{array}$ & $\begin{array}{c}\text { Produção } \\
\text { (150-180 dias) }\end{array}$ \\
R 1 & 40 & 100 & 40 & 100 \\
R 2 & 60 & 100 & 60 & 100 \\
R 3 & 80 & 100 & 80 & 100 \\
R 4 & 100 & 100 & 100 & 100 \\
\hline
\end{tabular}

Para a irrigação das plantas foi utilizada água proveniente de um açude localizado no centro das áreas experimentais cujas características, analisadas quimicamente no Laboratório de Irrigação e Salinidade (LIS) da Universidade Federal de Campina Grande (UFCG), estão apresentadas na Tabela 4.

Tabela 4. Características da água de irrigação da fazenda experimental

\begin{tabular}{lc}
\hline \multicolumn{1}{c}{ Características } & Valor \\
$\mathrm{pH}$ & 7,32 \\
Condutividade elétrica $\left(\mu \mathrm{S} \mathrm{cm} \mathrm{cm}^{-1}\right)$ & 880 \\
Cálcio $\left(\mathrm{mmol}_{\mathrm{C}} \mathrm{L}^{-1}\right)$ & 1,71 \\
Magnésio $\left(\mathrm{mmol}_{\mathrm{C}} \mathrm{L}^{-1}\right)$ & 2,29 \\
Sódio $\left(\mathrm{mmol}_{\mathrm{C}} \mathrm{L}^{-1}\right)$ & 4,30 \\
Potássio $\left(\mathrm{mmol}_{\mathrm{C}} \mathrm{L}^{-1}\right)$ & 0,58 \\
Carbonatos $\left(\mathrm{mmol}_{\mathrm{C}} \mathrm{L}^{-1}\right)$ & 0,00 \\
Bicarbonatos $\left(\mathrm{mmol}_{\mathrm{C}} \mathrm{L}^{-1}\right)$ & 3,38 \\
Cloretos $\left(\mathrm{mmol}_{\mathrm{C}} \mathrm{L}^{-1}\right)$ & 4,90 \\
Sulfatos $\left(\mathrm{mmol}_{\mathrm{c}} \mathrm{L}^{-1}\right)$ & 0,00 \\
Relaçãa de adsorção de sódio $\left(\mathrm{mmol}_{\mathrm{C}} \mathrm{L}^{-1}\right)^{0,5}$ & 3,05 \\
Classe de água para irrigação & $\mathrm{C}_{3}$ \\
\hline
\end{tabular}

A irrigação das parcelas foi feita com um sistema de irrigação composto de conjunto motobomba, através do qual se realizou a captação enquanto a condução da água foi pressurizada até a área experimental. A distribuição da água às parcelas foi controlada por registros e fornecida às plantas, através de gotejadores.

O cálculo das lâminas de irrigação foi baseado na equação a seguir, proposta por Guerra (2000) donde:

$$
\mathrm{AD}=(\mathrm{CC}-\mathrm{UA}) \mathrm{y} \cdot \mathrm{z}
$$

em que:
$\mathrm{AD}$ - água disponível, $\mathrm{cm}$

CC - umidade do solo em volume, na capacidade de campo $(0-1)$

UA - umidade atual do solo em volume, no momento da irrigação (0-1)

y - déficit hídrico estipulado (0-1)

$\mathrm{Z}$ - profundidade efetiva do sistema radicular, $\mathrm{cm}$

A área total de cada parcela era de $100 \mathrm{~m}^{2}$ na qual foram cultivadas 50 plantas espaçadas $2 \times 1 \mathrm{~m}$, com 24 plantas úteis $\left(48 \mathrm{~m}^{2}\right)$ e 26 plantas de bordadura $\left(52 \mathrm{~m}^{2}\right)$. O ciclo de semeio da mamona abrangeu até os 180 dias após o semeio (DAS) quando a produção de frutos e a determinação do teor de óleo das sementes foram feitas a partir do material coletado no final do experimento. Após o ciclo do semeio as plantas foram podadas drasticamente cortando-as a $30 \mathrm{~cm}$ do solo dando início ao ciclo do rebrote, igual ao do semeio, que durou 180 dias.

O teor de óleo nas sementes foi determinado no Laboratório da Embrapa CNPA em Campina Grande, através da técnica de Ressonância Magnética Nuclear (RMN), utilizando-se um espectrômetro marca Oxford 4000 de onda contínua para análise quantitativa, com base na emissão de corrente de radio frequência de $250 \mathrm{~m} \mathrm{~A}$, para um volume de amostra de $40 \mathrm{~cm}^{3}$ e tempo de integração de $20 \mathrm{~s}$.

Os dados foram analisados utilizando-se o programa estatístico SISVAR - ESAL - Lavras - MG, através do qual foi feita a análise de variância (ANAVA) aplicando-se o teste de Tukey a 0,05 de probabilidade para comparação das médias dos tratamentos qualitativos e análise de regressão para o fator quantitativo, de acordo com Ferreira (2000).

\section{Resultados E Discussão}

De acordo com os resultados estatísticos (Tabela 5) observa-se que os tratamentos de irrigação afetaram significativamente, em nível de $1 \%$, a produtividade média dos cultivares de mamona.

Os resultados da análise de variância (ANAVA), visualizados na Tabela 5, permitem observar que as plantas cujo solo foi mantido em capacidade de campo (100\% AD) durante todo o ciclo fenológico, obtiveram produtividade média de 5.010,42 $\mathrm{kg} \mathrm{ha}^{-1}$.

As cultivares BRS Paraguaçu e BRS Nordestina, tanto em semeio como em rebrote, não apresentaram diferenças significativas entre si com relação à produtividade média quando submetidas a diferentes tratamentos de irrigação. A regressão para o fator quantitativo água disponível referente à produtividade média das mamoneiras Paraguaçu e Nordestina, pode ser vista na Figura 1, constatando-se tendência linear crescente de produtividade na medida em que há variação crescente do conteúdo de água no solo ocorrendo diferença acentuada entre os tratamentos submetidos a diferentes regimes de irrigação, embora não havendo diferença significativa entre os cultivares com relação à variação de conteúdo de água, os mesmos apresentam respostas semelhantes.

A mamona, como a maioria das culturas, possui períodos críticos em que, quando submetidas a situações de deficiência hídrica, podem levar a alterações no desenvolvimento das plantas resultando, desta forma, em redução da produtividade 
Tabela 5. Resumo da análise de variância referente à produtividade média dos frutos dos cultivares de mamona BRS 149 Nordestina e BRS 188 Paraguaçu, em semeio e rebrote quando submetidos a diferentes regimes de irrigação

\begin{tabular}{|c|c|c|c|}
\hline \multirow{2}{*}{$\begin{array}{l}\text { Fonte de } \\
\text { variação }\end{array}$} & \multirow{2}{*}{ GL } & \multicolumn{2}{|c|}{ Quadrado médio } \\
\hline & & Semeio & Rebrote \\
\hline Cultivar & 1 & $134388,19^{\text {ns }}$ & $44444,82^{\mathrm{ns}}$ \\
\hline Regime de irrigação & 3 & $10979546,03^{* *}$ & $4398092,68^{* *}$ \\
\hline Cultivar $\mathrm{x}$ regime de irrigação & 3 & $846,31^{\text {ns }}$ & $16008,31^{\text {ns }}$ \\
\hline Blocos & 2 & $77543,53^{\text {ns }}$ & $62434,40^{*}$ \\
\hline Resíduo & 14 & 204586,99 & 41124,11 \\
\hline CV (\%) & & 11,84 & 10,24 \\
\hline Reg. polinomial linear & & $1.822,86^{\star *}$ & $140,963363^{* *}$ \\
\hline Reg. polinomial quadrática & & $162,76^{\mathrm{ns}}$ & $0,000417^{\text {ns }}$ \\
\hline Reg. polinomial cúbica & & $0,01^{\mathrm{ns}}$ & $0,887520^{\mathrm{ns}}$ \\
\hline Resíduo & & 204586,99 & 2,5117 \\
\hline Cultivares & \multicolumn{3}{|c|}{ Médias das produtividades $\left(\mathrm{kg} \mathrm{ha}^{-1}\right)$} \\
\hline Nordestina & & $3266,66 \mathrm{a}$ & $1937,70 \mathrm{a}$ \\
\hline Paraguaçu & & $3416,32 \mathrm{a}$ & $2023,80 \mathrm{a}$ \\
\hline DMS & & 177,56 & 396,04 \\
\hline Regime de irrigação 1 & & 1815,50 & 1185,36 \\
\hline Regime de irrigação 2 & & 2842,47 & 1539,01 \\
\hline Regime de irrigação 3 & & 3697,56 & 2048,90 \\
\hline Regime de irrigação 4 & & 5010,41 & 3149,78 \\
\hline
\end{tabular}

Significativos a $0,05\left(^{*}\right)$ e a $\left.0,01{ }^{* \star}\right)$ de probabilidade; (ns) não significativo; médias seguidas de mesma letra na vertical não diferem entre si $(p<0,05)$

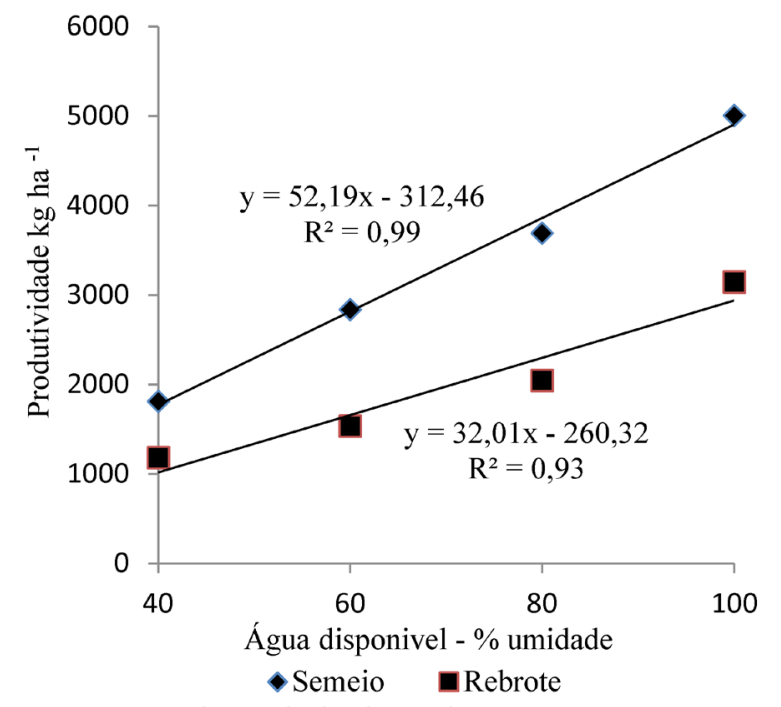

Figura 1. Produtividade das cultivares BRS Paraguaçu e BRS Nordestina em função do regime de irrigação (40, 60, 80 e $100 \%$ da água disponível no solo, nas fases de floração e frutificação)

final. Silva et al. (2009) obtiveram produtividade total de $1.317,09 \mathrm{~kg} \mathrm{ha}^{-1}$ para uma lâmina aplicada de $487,5 \mathrm{~mm}$. Savy Filho et al. (2007) estudaram o cultivar IAC-2028, avaliada em relação à produtividade de grãos, em três locais do estado de São Paulo (Adamantina, Pindorama e Campinas) e em quatro safras agrícolas: 1999/2000, 2002/2003, 2003/2004 e 2006. A produtividade média foi de $1.950 \mathrm{~kg} \mathrm{ha}^{-1}$. Lacerda et al. (2009) encontraram resultados semelhantes (as plantas cujos tratamentos foram submetidos aos maiores conteúdos de água do solo, se apresentaram mais eficientes com relação à sua capacidade fotossintética). Maiores produtividades 2.353,66; $2.248,07$ e $2.872,48 \mathrm{~kg} \mathrm{ha}^{-1}$, para os cultivares IAC Guarani,
Mirante 10 e BRS Paraguaçu, foram obtidas num tratamento de irrigação com 913,45 mm, Freitas et al. (2010).

Freitas et al. (2010) observaram aumento linear para a IAC Guarani e quadrático para a BRS Paraguaçu, no número de frutos por racemo e, em contrapartida, aumento na produção. Biscaro et al. (2012) encontraram que a aplicação de água a $150 \%$ da evapotranspiração aumentou em $80 \%$ a produtividade em relação ao tratamento que não recebeu irrigação suplementar.

As fases de floração e frutificação são as que apresentam maiores consumos de água sendo, portanto, consideradas fases críticas (Carvalho et al., 2004). Em função dessas condicionantes observa-se, na Figura 1 que, à medida que a disponibilidade de água no solo se elevou nessas fases, tanto no semeio como no rebrote houve um acréscimo tanto em qualidade como em quantidade dos frutos da mamoneira. A resposta mais drástica das plantas ao déficit hídrico, segundo McCree \& Fernández (1989), consiste no decréscimo da produção da área foliar, do fechamento dos estômatos, da aceleração da senescência e da abscisão das folhas. Quando as plantas são expostas a situações de déficit hídrico exibem, com frequência, respostas fisiológicas que resultam de modo indireto na conservação da água no solo como se estivessem economizando para períodos posteriores. A água, além de ser necessária ao crescimento das células, é um elemento essencial para a manutenção da turgescência. Souza et al. (2000) também encontraram, trabalhando com gergelim e algodão herbáceo, que estresses hídricos aplicados a diferentes fases fenológicas diminuíram a produtividade em virtude da diminuição da fotossíntese.

Durante o período da frutificação no semeio, quando a água do solo foi mantida a 40, 60 e $80 \%$ da água disponível, a produtividade da mamoneira aumentou 275,98; 176,26 e $135,50 \%$, respectivamente, quando comparada com a do solo na capacidade de campo ( $100 \%$ da água disponível), no rebrote (período de frutificação). A água do solo foi mantida a 40, 60 e a $80 \%$ da água disponível a produtividade da mamoneira aumentou 265,$72 ; 204,66$ e $153,73 \%$ respectivamente quando comparado com o solo em capacidade de campo $(100 \%$ da água disponível).

Na Tabela 6 são apresentados os resultados das análises de variância (ANAVA) do teor de óleo das sementes dos cultivares de mamona BRS 188 Paraguaçu e BRS 149 Nordestina para o semeio e para o rebrote; observa-se, que em ambos os ciclos, que os cultivares não apresentaram diferenças significativas entre si quanto à variação do conteúdo de água do solo ao longo do ciclo de 180 DAS; mesmo assim e no tocante aos diferentes níveis de água a que foram submetidas, as plantas apresentaram diferenças estatísticas significativas a nível de1\% $(\mathrm{p}<0,01)$.

O estresse hídrico causado pela diminuição do conteúdo de água no solo provocou reduções no teor de óleo, as sementes das plantas conduzidas a $100 \%$ de $\mathrm{AD}$ apresentaram em média, para o semeio, teor de óleo de $51,08 \%$ enquanto os tratamentos submetidos a estresse hídrico por deficiência, para os níveis de 40,60 e $80 \%$ AD apresentaram teores médios de 43,43; 44,$13 ; 47,66 \%$ de óleo, respectivamente. Na condição de rebrote o teor de óleo das sementes das plantas conduzidas a $100 \%$ de AD apresentou, em média, teor de óleo de 51,10\% enquanto os tratamentos que foram submetidos a estresse hídrico por deficiência, para os níveis de $40 ; 60$ e $80 \%$ AD, 
Tabela 6. Resumo das análises de variância referente à variável teor de óleo das sementes da mamoneira

\begin{tabular}{|c|c|c|c|}
\hline \multirow{2}{*}{ Fonte de variação } & \multirow{2}{*}{ GL } & \multicolumn{2}{|c|}{ Teor de óleo das sementes } \\
\hline & & Semeio & Rebrote \\
\hline & & \multicolumn{2}{|c|}{ Quadrado médio } \\
\hline Cultivar & 1 & $0,01^{\mathrm{ns}}$ & $1,73^{\text {ns }}$ \\
\hline$A D$ & 3 & $74,69^{\star \star}$ & $47,28^{\star \star}$ \\
\hline Interação & 3 & $0,01^{\mathrm{ns}}$ & $0,46^{\text {ns }}$ \\
\hline Blocos & 2 & $3,00^{\text {ns }}$ & $13,98^{\text {ns }}$ \\
\hline Resíduo & 14 & 7,01 & 7,01 \\
\hline \multirow[t]{2}{*}{ CV \% } & & 5,68 & 3,32 \\
\hline & & \multicolumn{2}{|c|}{ (AD) } \\
\hline Reg. pol. linear & & $210,41^{\star \star}$ & $210,41^{\star *}$ \\
\hline Reg. pol. quadrática & & $11,07^{\mathrm{ns}}$ & $11,07^{\text {ns }}$ \\
\hline Reg. pol. cúbica & & $2,61^{\text {ns }}$ & $2,61^{\text {ns }}$ \\
\hline \multirow[t]{2}{*}{ Resíduo } & & 7,01 & 7,01 \\
\hline & & \multicolumn{2}{|c|}{ Teor de óleo das sementes (\%) } \\
\hline Nordestina & & $46,55 \mathrm{a}$ & $47,49 a$ \\
\hline Paraguaçu & & $46,60 \mathrm{a}$ & $48,03 \mathrm{a}$ \\
\hline DMS & & 2,31 & 1,38 \\
\hline Regime de irrigação 1 & & 43,433 & 44,42 \\
\hline Regime de irrigação 2 & & 44,133 & 46,94 \\
\hline Regime de irrigação 3 & & 47,666 & 48,59 \\
\hline Regime de irrigação 4 & & 51,083 & 51,10 \\
\hline
\end{tabular}

GL - Grau de liberdade; CV - Coeficiente de variação; DMS - Diferença mínima significativa; AD - Água disponível; Significativo a 0,05 (*) e a 0,01(**) de probabilidade; (ns) Não significativo; médias seguidas de mesma letra na vertical não diferem entre si $(p<0,05)$

apresentaram teores médios de 43,42; 46,94; 48,59\% de óleo, respectivamente.

Barros Júnior et al. (2008) observaram que o estresse hídrico reduziu o teor de óleo nas sementes em decorrência da baixa qualidade das sementes produzidas por plantas conduzidas a $60 \%$ de $\mathrm{AD}$, o mesmo sendo obtido para o tratamento mantido a $80 \%$ de $\mathrm{AD}$; para este último, a redução foi de mais de $53 \%$ na produção de óleo em relação ao teor de óleo produzido por plantas que tiveram a disponibilidade de água mantida em capacidade de campo. Já Biscaro et al. (2012) afirmam que o aumento das lâminas de irrigação baseadas na evapotranspiração da cultura proporcionou incremento significativo da maioria dos componentes da produção e da produtividade da cultura, sem alterar o teor de óleo contido nas sementes. Segundo Souza et al. (2007), após a estação chuvosa ou durante a ocorrência de veranicos a suplementação hídrica pode contribuir para o aumento da produtividade uma vez que, por se tratar de uma planta de crescimento indeterminado e existindo água disponível no solo, a planta continuará a florescer e a produzir.

O teor médio de óleo $(51,10 \%)$ obtido nas sementes das plantas conduzidas sem estresse hídrico é superior ao da faixa de 45 a $49 \%$ previstas por Azevedo \& Beltrão (2007) e EMBRAPA (2002) para os cultivares Nordestina e Paraguaçu. Laureti (2002) registrou em trabalhos com o híbrido "HD 912" de mamona, reduções de até 50,70\% no teor de óleo das sementes quando irrigadas com reduções progressivas nas lâminas de água, proporcionais a 75,50 e $25 \%$ da ETc.

A regressão para o fator quantitativo água disponível se encontra na Figura 2 verificando-se que, o conteúdo de água disponível no solo se elevou, o teor de óleo apresentou tendência linear crescente com acréscimos de $0,1 \%$ de óleo para cada aumento unitário de água disponível.

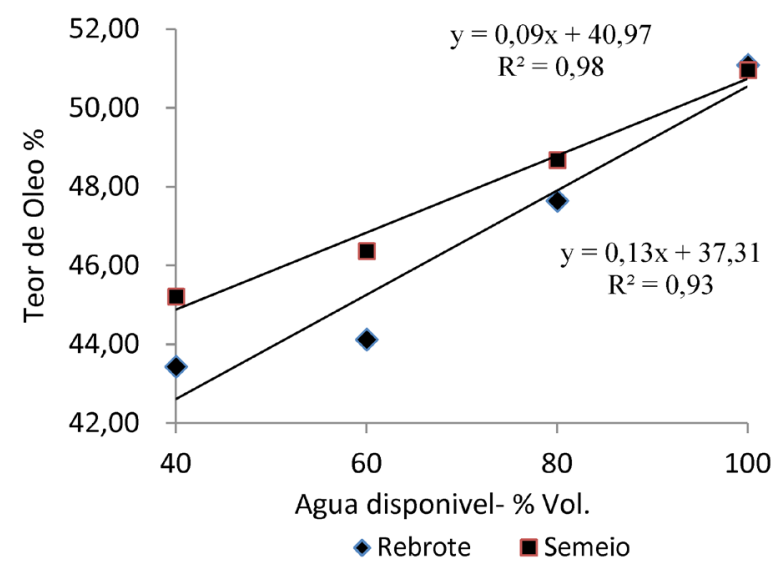

Figura 2. Teor de óleo das sementes das cultivares BRS - Paraguaçu BRS - Nordestina em função do conteúdo de água disponível no solo, nas fases de crescimento e frutificação

\section{Conclusões}

1. As cultivares de mamona BRS Paraguaçu e BRS Nordestina se comportaram estatisticamente igual quando submetidas a diferentes regimes de irrigação, tanto no semeio como no rebrote;

2. Os regimes de irrigação estudados aumentaram significativamente a produtividade dos cultivares, tanto quantitativa como qualitativamente.

3. Os cultivares mantidos durante todo o ciclo a $100 \%$ da AD foram mais eficientes na conversão de água em produtividade, com aumento linear crescente de produtividade à medida em que a disponibilidade hídrica no solo foi elevada, ocorrendo diferença acentuada entre os tratamentos.

4. O rebrote da cultura, obtido pela poda drástica da planta aos 180 dias, apresentou uma produtividade semelhante à do semeio, em todos os regimes de irrigação, com elevado padrão de qualidade do produto final.

\section{Literatura Citada}

Ambroszczyk, A. M.; Cebula, S.; Sękara, A. The effect of plant pruning on the light conditions and vegetative development of eggplant (Solanum melongena L.) in greenhouse cultivation. Vegetable Crops Research Bulletin, v.68, p.57-70, 2008.

Amorim Neto, M. da S.; Araújo, A. E. de; Beltrão, N. E. de M. Clima e solo. In: Azevedo, D. M. P. de; Lima, E. F. (ed). O agronegócio da mamona no Brasil. 2.ed Brasília: Embrapa Informação Tecnológica. 2007. 504p.

Azevedo, D. M. P. de; Beltrão, N. E. de M. O agronegócio da mamona no Brasil. 2.ed. Brasília: Embrapa Informação Tecnológica. 2007. 504p.

Barreto, A. N. Quantificação de água necessária para a mamoneira irrigada com base nas constantes hídricas do solo. In: Congresso Nacional da Mamona, 1, 2004, Campina Grande. Anais...Campina Grande: EMBRAPA, 2004. CD-Rom

Barros Júnior, G.; Guerra, H. O. C.; Cavalcanti, M. L. F.; Lacerda, R. D. de. Consumo de água e eficiência do uso para duas cultivares de mamona submetidas a estresse hídrico. Revista Brasileira de Engenharia Agrícola e Ambiental, v.12, p.350-355, 2008. 
Beltrão, N. E. de M.; Cartaxo, W. V.; Pereira, S. R. de P.; Soares, J. J; Silva, O. R. R. F. O cultivo sustentável da mamona no semiárido brasileiro. Campina Grande: Embrapa Algodão, 2006. 62p.

Biscaro, G. A.; Vaz, M. A. B.; Giacon, G. M.; Gomes, E. P.; B. da Silva, S.; Motomiya, A. V. de A. Produtividade de duas cultivares de mamona submetidas a diferentes lâminas de irrigação suplementar, Revista Brasileira de Engenharia Agrícola e Ambiental, v.16, p.925-930, 2012.

Carvalho, J. A.; Santana, M. J.; Pereira, G. M.; Pereira, J. R. D.; Queiroz, T. M. Níveis de déficit hídrico em diferentes estádios fenológicos da cultura da berinjela (Solanum melongena L.).Engenharia Agrícola, v.24, p.730-735, 2004.

Cavalcanti, M. L. F.; Fernandes, P. D.; Gheyi, H. R.; Barros Júnior, G.; Soares, F. A. L. Siqueira, E. da C. Tolerância da mamoneira BRS 149 à salinidade: Germinação e características de crescimento. Revista Brasileira de Engenharia Agrícola e Ambiental, v.9, p.57-61, 2005.

Cebula, S. Effect of plants pruning on the growth, yields, and fruit quality of two cultivars of eggplant (Solanum melongena L.) in greenhouse production. Acta Agrictural, v.34, p.1-11. 1996.

Costa, M. N. da; Pereira, W. E.; Bruno, R. L. de A.; Freire, E. C.; Nóbrega, M. B. de M.; Milani, M.; Oliveira, A. P. de. Divergência genética entre acessos e cultivares de mamoneira por meio de estatística multivariada. Pesquisa Agropecuária Brasileira, v.41, p.1617-1622, 2006.

Diniz, B. L. M. T.; Távora, F. J. A. F.; Diniz Neto, M. A. Manipulation of the castor bean growth through the pruning at different planting densities. Revista Ciencia Agronômica, v.40, p.570-577, 2009.

EMBRAPA - Empresa Brasileira de Pesquisa Agropecuária. Centro Nacional de Pesquisa de Solos (Rio de Janeiro, RJ). Manual de métodos de análise de solo. 2.ed. Rio de Janeiro: Embrapa CNPS, 1997. 212p.

EMBRAPA - Empresa Brasileira de Pesquisa Agropecuária. BRS - 149 Nordestina e BRS - 188 Paraguaçu. Campina Grande: EMBRAPA Algodão. 2002. 2p. Folder.

EMBRAPA - Empresa Brasileira de Pesquisa Agropecuária. Sistemas de produção. 4. Correção do solo e adubação. Versão eletrônica. Nov/2007. http://sistemasdeproducao. cnptia.embrapa.br. 5 Abr. 2012

Ferreira, P. V. Estatística aplicada a agronomia. 3.ed. Maceió: EDUFAL, 2000. 422p.
Freitas, C. A. S. de, Bezerra, F. M. L.; Silva, A. R. A. da; Pereira Filho, J. V.; Feitosa, D. R. C. Comportamento de cultivares de mamona em níveis de irrigação por gotejamento em Pentecoste, CE. Revista Brasileira de Engenharia Agrícola e Ambiental, v.14, p.1059-1066, 2010.

Gomes, E. P.; Testezlaf, R. Manejo de irrigação na tomaticulturade-mesa. http://www.feagri.unicamp.br/tomates/pdfs/ manejoirrig.pdf. 10 Nov. 2007.

Guerra, H. O. C. Física dos solos. Campina Grande: UFCG, 2000. 173p.

Lacerda, R. D. de; Guerra, H. O. C.; Barros Júnior, G. Influência do déficit hídrico e da matéria orgânica do solo no crescimento e desenvolvimento da mamoneira BRS 188 - Paraguaçu. Revista Brasileira de Ciências Agrárias, v.4, p.440-448, 2009.

Laureti, D. Fabbisogni idrici del ricino (Ricinus communis L.) mediante l’impiego di coefficienti colturali e de déficit ídrico. Agroindustria, v.1, p.165-167, 2002.

McCree, K. J.; Fernández, C. J. Simulation model for studying physiological water stress responses of whole plants. Crop Science, v.29. p.353-360. 1989.

Oliveira, I. J. de; Zanotto, M. D. Eficiência da seleção recorrente para redução da estatura de plantas em mamoneira (Ricinus communis L.). Ciência e Agrotecnologia, v.32, p.1107-1112, 2008 .

Ramos, N. P.; Amorim, E. P.; Galli, J. A.; Martins, A.L.M.; Brancalião, S. R.; Savy Filho, A.; Bolonhezi, D. Desempenho vegetativo de mamona sob diferentes sistemas de manejo do solo. In: Congresso Brasileiro de Mamona, 2, 2006, Aracajú. Anais...Campina Grande: Embrapa Algodão, 2006. CD-Rom

Savy Filho, A.; Amorim, E. P.; Ramos, N. P.; Martins, A. L. M.; Cavichioli, J. C. IAC 2028: Nova cultivar de mamona. Pesquisa Agropecuária Brasileira, v.42, p.449452, 2007.

Silva, S. M. S.; Gheyi, H. R.; Beltrão, N. E. de M.; Santos, J. W. dos; Soares, F. A. L. Dotações hídricas em densidades de plantas na cultura da mamoneira cv. BRS Energia. Revista Brasileira de Ciências Agrárias, v.4, p.338-348, 2009.

Souza, A. dos S.; Távora, F. J. A.; Pitombeira, J. B.; Bezerra, F. M. L. Épocas de plantio e manejo da irrigação para a mamoneira. II - Crescimento e produtividade. Revista Ciência Agronômica, v.38, p.422-429, 2007.

Souza, J. G. de; Beltrão, N. E. de M.; Santos, J. W. dos. Fisiologia e produtividade do gergelim em solo com deficiência hídrica. Revista de Oleaginosas e Fibrosas, v.4, p.163-168, 2000. 